\title{
Strategy of Developing Cross-Border Electric Commerce for the Tea Enterprises in Anhui Province
}

\author{
WEI Xiaobo \\ Department of Economics and Management \\ Xijing University, \\ Xi'an 710123, China
}

\begin{abstract}
Tea products have always occupied the higher share of agricultural exports in Anhui province. In recent years, the rapid development of cross-border e-commerce has become an important choice for the tea enterprises. On the basis of current situation, researchers analyze the advantage of the business model and finally explore the development strategy of cross-border e-commerce for Anhui tea enterprises from product marketing, platform construction, international logistics, customs clearance, payment and other aspects, with the purpose of providing reference for these relevant industries.
\end{abstract}

Keywords-Anhui tea; Tea enterprises; Cross-border Ecommerce; Cross-border exports

\section{INTRODUCTION}

China is famous for its rich tea products. Tea export has become a characteristic industry in many provinces to develop local agricultural economy. As the country's main producing areas, Anhui's tea production and export volume have been ranked top in recent years. At present, tea garden area in this province has been developed to more than 1500 square kilometers and achieved processing output value of more than 140 billion Yuan. Data shows that, in 2015, Anhui province tea exports reached the record in the province's largest single agricultural exports, about 224 million US dollars, up 17.14\% from last year. The province has more than 7,000 large and small tea enterprises, among them there are 17 companies which were selected in the year of 2014 National Tea hundred enterprises such as Anhui Tea Company of Import and Export, Liu'an Leaf Limited Liability Company and HuangShan Xinanyuan Organic Tea Corporation[1]. In addition, there are hundreds of time-honored tea enterprises. But most of them are small and medium size. Those companies attaching to the tea producing areas are not enough intensive and contiguous. Even they show weak integration of supply chain, and have low level application of information technology and new business model. Thus it is difficult to form the advantages of scale and brand premium, so the export profit level is not high for them.

In the brand influence, Anhui's "Yellow mountain fuzz tip", "Taiping Houkui Tea", "Keemun Black Tea", "liu’an leaf Tea" are famous for their unique natural conditions[2]. Anhui tea export market is mainly concentrated in Africa and the Middle East, followed by Japan, the United States, Russia, Hongkong, the European Union and other regions. At present, Anhui tea export enterprises have encountered four impacts from domestic production costs, international exchange rate fluctuations, trade barriers and international political environment. Their economic efficiency has obviously weakened and showed unfavorable or low profit situation. Thus Anhui tea enterprises are not willing to invest too much to develop the international market, the export areas are still in less developed countries and regions. The products' structure is still in low value-added, OEM, bulk of casual tea, raw tea etc..

\section{ANALYSIS OF THE ADVANTAGES OF CROSS-BORDER E- COMMERCE BUILDING A FOREIGN TRADE INDUSTRY CHAIN}

Since the financial crisis, although there was the sluggish growth in China's traditional foreign trade, Cross-border ecommerce has been active and become an important force to boost China's foreign trade. This situation prompted tea export enterprises must to explore cross-border e-commerce to expand the business. Cross-border e-commerce can use new technologies and trade means to build a clear and complete foreign trade industry chain for enterprises business such as overseas market development, customs clearance payments, international logistics and other services. According to the Provincial Department of Commerce, in 2015, Anhui had more than 22000 import and export business enterprises, as well as more than 220 countries and regions with trade relations. Anhui cultivated the "Wanshangtong" and other foreign trade comprehensive service enterprises, among them Yellow mountain fuzz tip tea was sold abroad through the "Wanshangtong" via the Internet. These platforms not only create economic benefits, but also spread Anhui's culture.

If tea enterprises carry out cross-border e-commerce, they can gain the advantages as follows: firstly, it can simplify the process of foreign trade, and eliminate many redundant procedures. By connecting tea product providers (such as producers or dealers) and foreign consumers directly, stripping traditional channels of intermediaries (such as importers, wholesalers, distributors, retailers)informally, cross border ecommerce platforms can improve sales efficiency and increase profit margins, give consumers more benefits. Secondly, enterprises participate in foreign trade easier than before. These enterprises owing quality products would encounter many 
difficulties when they run the traditional trade business for the cumbersome procedures of foreign trade qualification. But they can directly participate in the international exports by using cross-border e-commerce platforms. Relying on the cooperation and opening up of these platforms' natural characteristics, small trade business can combine with many enterprises on the whole industry chain which can provide support of customs clearance, settlement and cross-border logistics, so as to enhance the competitiveness of enterprises. Thirdly, it breaks the boundaries of time and space, and brings more business opportunities. The traditional market channel is a single and closed in the past. The restriction of time and space in the market has hindered economic and trade exchanges. In the information era, sellers use digital means to publish product information and search for buyers. The cost of network communication has been reduced and business negotiations have become convenient and rapid, so opportunities have been increased significantly.

\section{THE STRATEGY OF CARRYING OUT CROSS-BORDER E- COMMERCE FOR TEA ENTERPRISES IN ANHUI PROVINCE}

\section{A. Doing a good job of product quality and brand building for expanding marketing coverage}

Product quality has always been the fundamental guarantee for enterprise Everlasting. China's tea industry faces the overcapacity problem, so it has to be exported to foreign countries by relying on quality and characteristics. The production of Anhui's green tea has been accounted for a larger proportion, yet black tea, white tea and other categories need to be supported. Meanwhile organic tea has to be kept up with the pace. There are still some companies which have undeveloped production craft and processing technique, resulting to that product quality and excellent raw materials are not match. So firstly the companies should popularize new knowledge of tea production and processing through the means of e-commerce, and actively introduce clean, continuous and automated manufacturing lines. Secondly, those enterprises should expand the production scale of staple tea and improve the deep processing technique. Thirdly, they should focus on the development of fine, blending tea and provide multi- categories of tea-related food (such as instant tea with bag) and accessories products.

In the market segment, those enterprises should not only pay attention to the influence of overseas Chinese communities, but also to study the foreign consumer culture and diet characteristics[3]. By doing this they can tap the added value and shape the brand of tea exports well. In the choice of the target market, businessmen should focus on the main crossborder export countries and regions that have relationship with Anhui, such as Europe, United States and other developed countries. Meanwhile they should pay attention to the new emerging markets which are small countries along the Silk Road. In the market positioning, young people abroad do not know too much about Chinese tea culture, they pursue the convenience of shopping, the taste of products, the mood of consumption and the passion for online shopping, thus domestic exporters should make extensive use of Internet social media and search engines to design tailored advertisements for them. In the consumer experience and service, sellers should innovate marketing strategy and sales channels. With coupons, gifts, trial samples and other means of promotion, they can establish a physical experience store or settling in the local shop through agents. Moreover they can take the FMCG way to expand the market by using On-line to Off-line to share information with overseas retailers.

\section{B. Small and medium-sized tea vendors focus on B2C business, leading enterprises focus on $B 2 B$ business}

Currently cross-border e-business platforms mainly include three categories: Integrated Platform (such as AliExpress, etc.), Vertical Platform(such as Light in the Box, SIX TEA,etc.), service providers (such as Osell.com, etc.). Combining with their own talent, technology and resource advantages, Anhui tea enterprises can develop cross-border e-business step by step, from the basic information service, to the online transactions, finally to the whole industry chain services.

Small and medium-sized enterprise can mainly focus on B2C and moderately develop B2B. For those individuals who have not yet set foot in the cross-border e-business, small and micro- sellers, by publishing product information on the crossborder platform, they can choose to non-site marketing, and gradually accumulate overseas market experiences on the initial stage. For those small and medium enterprises with certain strength, then do not launch network promotion blindly. According to the financial situation to make good use of the existed platforms, they can choose the site with a long-term buyers being accumulated. In this way, they can achieve maximum efficiency, for their input and output ratio is the best. When selecting the platforms, those sellers should consider the factors of its multi-language, accumulated customers, the profession reputation, large amount of page view and not too expensive price. In addition, with the explosive growth of mobile Internet users, the platform needs to operate on the mobile side at the same time, and the data analysis of the mobile users should be conducted to guide the enterprise management decisions. If necessary, these companies should consider contract out their non-core business to the Internet service providers. For these leading enterprises, they should focus on B2B, and B2C trade should be added as a supplement. They need to choose the platforms which can improve their management level and integrity degree, or to use policies and resources to build or cultivate their own industry platform. Self-built platform can be customized to highlight the personalized features according to their own needs, with the more autonomy, the more perfect functions. The promotion and operation cost of this platform are relatively saving, and it is also beneficial to the data accumulation and brand influence.

\section{The enterprises should hold together to settle in Cross- border e-commerce industry park in the form of alliances and take the mixed logistics model}

Nowadays Fujian, Zhejiang and other places have been in the forefront of cross-border exports of tea products in virtue of the first advantage. So Anhui tea enterprises should actively introduce talents to cultivate business owners and professional operation teams and to settle in the province of e-commerce park by making good use of relevant policies. Only in this way, 
can they form a joint force to enhance the tea brand influence and open the international market. As early as May 2015, there were nine tea enterprises setting up business association to promote the Wannan, Wanxi tea industry. Through the establishment of enterprises and commodity information database, the alliance can analysis both domestic and foreign markets to achieve visual tracking of the full flow of tea production and management. The union also can integrate the tea industry chain including many partners(such as e-business platform, logistics providers, trade services enterprises, financing companies, e-commerce training institutions, etc.) to achieve a package of services involving customs clearance, inspection, logistics, finance, talent and so on. This would effectively promote business linkage of online to offline and enterprise collaboration.

In the choice of logistics tea enterprises can take the model of mixed logistics through the joint establishment, leasing, and self-built way. According to the actual needs of business operations, this mode can design logistics lines and transit methods flexibly. It can also integrate logistics resources in the park, improve efficiency, and cut costs. Some customers hope to get the goods quickly, who are not sensitive to the price, thus the companies can choose the mode of special line overseas warehouse. By responding to customers' needs in a timely manner, and because of overseas dumping, the goods of the second packaging and returning are easier, thereby the mode are enhancing customer satisfaction. Of course for these customers caring about the price but not for the timeliness, the companies can choose direct mail overseas warehouse mode to reduce the cost.

\section{Establishing extensive contacts with customs, taxation} departments and others to optimize the business processes

Small and medium-sized enterprises hope to increase the efficiency of customs clearance, improve the convenience of tax rebates and cut the cost of trade. At present, Anhui (Shushan) cross-border e-business park has built the province's only unified customs clearance platform, which directly connected with the customs to handle bulk of business under its effective supervision[4]. The platform also can take advantage of automated "cloud warehouse" system which is the leading domestic level, to achieve fast customs clearance based on credit. Tea enterprises, e-commerce platforms, payment and logistics providers can automatically upload data, after the customs examination and processing, the parcels will be sent to the whole world.

At present, cross-border payments have been able to use both foreign exchange and Renminbi. Cross border exports can be paid in a variety of ways, such as bank transfers, credit cards, and the third party payments. Cross-border B2B business currently mainly relies on credit, bank remittance and other traditional payment; and Cross-border B2C business mainly uses online payment---such as the third-party payment tools: PayPal, international payment, etc. --to complete the transaction. Tea companies should take full account of the ways that the platform supports and respect the needs of buyers, then choose the most favorable way to themselves. With the RMB entering into the SDR basket, Hefei also carried out the RMB cross-border payment of business innovation, for which enterprises should take the initiative to contact with the relevant units and use high-quality cross-border RMB settlement services. Settlement problems (for example, personal annual foreign exchange equivalent to \$50 thousand limit) have been a hot concern. For these small and mediumsized individual sellers in accordance with the provisions of industry and commerce, taxation and customs departments, the inspection and quarantine authorities should allow them to handle cross -border trade with a separate personal exchange settlement account and deal with personal foreign exchange receipts and payments through the Internet bank; in addition the departments should support the third party payment institutions to provide cross-border payment service, and encourage banks to dock with the customs commodity inspection platform to achieve online settlement.

\section{SUMMARY}

During the 13th Five-Year Plan period, China's business and trade environment, industrial base and conditions are constantly adjusted and optimized. In the domestic area, with China's economy entering the new normal, enterprises need to reform from the supply side, and strive to adapt to the consumer market in the brand and quality needs[5]. The original enterprises which relied on investment-driven, production-driven now have to consider technology-driven and business model innovation to bring new development. On the outside, the Southeast Asian countries use lower costs to attract industrial transfer, and Silk Road countries and emerging economies have brought new markets, then China's traditional processing trade, labor-intensive production and export are bound to face challenges and opportunities. Thus the tea enterprises in Anhui province must develop cross-border ecommerce, from the market conditions, credit environment, the difference between the marketing channels to achieve high value-added transfer, thereby promoting the breakthrough and upgrading of traditional industries.

\section{REFERENCES}

[1] Wang Wei. "liu'an leaf Tea" as an Example to Explore the Characteristics and Development Countermeasures of Green Tea Industry in West Anhui Province [D]. Capital University of Economics and Business, 2014.

[2] Shen Yanfei. An Analysis of the Competitiveness of China's Tea Industry in International Trade [J]. Fujian Tea, 2016, 09: 47-48.

[3] Zhang Peng. Trade Situation and its Expansion Space of China's Tea Exports to German [J]. Foreign Trade Practice, 2016, 09: 56-59.

[4] Wang Yi, He Jun. Reflections on the Development of Cross-border Ecommerce in Hefei City [J]. Modern business, 2016, 17: 99-101.

[5] Zhang Jian. Analysis on the Online Sales Strategy of Tea Based on Supply Side Reform and Data Mining [J]. Commercial Economics Research, 2016, 12: 53-54. 